\title{
LC-MS/MS method development for quantification of doxorubicin and its metabolite 13-hydroxy doxorubicin in mice biological matrices: Application to a pharmaco-delivery study
}

${ }^{1}$ Dipartimento di Scienze Biomediche e Cliniche "Luigi Sacco", Università degli Studi di Milano, Italy

${ }^{2}$ Dipartimento di Scienze Biomediche, Chirurgiche ed Odontoiatriche, Sezione di Tossicologia Forense, Università degli Studi di Milano, Italy

\section{Correspondence}

Roberta Ottria, Università degli Studi di Milano-Dipartimento di Scienze Biomediche e Cliniche "Luigi Sacco," Via G.B. Grassi 74, 20157 Milano, Italy.

Email: roberta.ottria@guest.unimi.it

\begin{abstract}
This study describes the development of simple, rapid and sensitive liquid chromatography tandem mass spectrometry method for the simultaneous analysis of doxorubicin and its major metabolite, doxorubicinol, in mouse plasma, urine and tissues. The calibration curves were linear over the range $5-250 \mathrm{ng} / \mathrm{mL}$ for doxorubicin and $1.25-25 \mathrm{ng} / \mathrm{mL}$ for doxorubicinol in plasma and tumor, over the range $25-500 \mathrm{ng} / \mathrm{mL}$ for doxorubicin and $1.25-25 \mathrm{ng} / \mathrm{mL}$ for doxorubicinol in liver and kidney, and over the range $25-1000 \mathrm{ng} / \mathrm{mL}$ for doxorubicin and doxorubicinol in urine. The study was validated, using quality control samples prepared in all different matrices, for accuracy, precision, linearity, selectivity, lower limit of quantification and recovery in accordance with the US Food \& Drug Administration guidelines. The method was successfully applied in determining the pharmaco-distribution of doxorubicin and doxorubicinol after intravenously administration in tumor-bearing mice of drug, free or nano-formulated in ferritin nanoparticles or in liposomes. Obtained results demonstrate an effective different distribution and doxorubicin protection against metabolism linked to nano-formulation. This method, thanks to its validation in plasma and urine, could be a powerful tool for pharmaceutical research and therapeutic drug monitoring, which is a clinical approach currently used in the optimization of oncologic treatments.
\end{abstract}

\section{KEYWORDS}

doxorubicin, doxorubicinol, LC-MS/MS, nano-formulated drug, quantification

\section{1 | INTRODUCTION}

Doxorubicin (DOX), an anthracycline glycoside antibiotic, is an exceptionally good antineoplastic agent and is widely used in the treatment of various cancers, including lung, ovarian and breast cancer and malignant lymphoma (Duggan \& Keating, 2011). However, long-term clinical use is limited due to the development of a progressive dose-dependent cardiomyopathy that irreversibly evolves toward congestive heart failure (Ho, Fan, Jou, Wu, \& Sun, 2012). The current thinking is that DOX

Abbreviations used: $\mathrm{CS}$, calibration standard; \%CV, percentage coefficient of variance; DAU, daunorubicin hydrochloride; DOX, doxorubicin; DOXol, doxorubicinol; HQC, high quality control; LLE, liquid-liquid extraction; LOD, limits of detection; LOQ, limits of quantification; LQC, low quality control; MQC, medium quality control; QC, quality control; \%RSE, percentage relative standard error. is toxic per se but gains further cardiotoxicity after one-electron reduction with reactive oxygen species overproduction or two-electron reduction with conversion to a secondary alcohol metabolite doxorubicinol (DOXol). It became clear that is essential to quantify this toxic metabolite of DOX in as much biomatrices as possible to study its distribution in the organism after drug administration to understand better the side effect mechanisms linked to DOX treatment. Furthermore, the antitumor activity of the drug was noticeably enhanced when it was nano-formulated. Indeed, DOX has been found to be more effective in mice when loaded in nano-drug delivery systems such as polymeric nanoparticles, liposomes and bionanoparticles. Moreover nano-formulation protects DOX from undesired metabolism reducing the formation of toxic derivatives as DOXol (Lianga et al., 2014; Park et al., 2009). Actually, it is well-known that nano-formulation improves drug bioavailability, delivery and accumulation to the tumor site. At the 
same time, the tumor targeting of the drug implies the reduction of organ-sensitive toxicity because of the better tissue biodistribution. Moreover, slow drug release from a storage structure help to enhance the therapeutic index and reduce side effects (Rao et al., 2015). Although the mechanisms by which targeted drugs are more efficient is becoming increasingly clear, only few details about less toxicity associated to nanoparticle-loaded DOX than the free drug are available. Information about the biodistribution of DOX delivered by nanoparticles and, in particular, that of its cardiotoxic metabolite DOXol should lead to a better understanding of the mechanisms related to reduced nano-formulated drug toxicity. Various analytical methods in which detection limits, adequate to analyze plasma or serum from patients receiving conventional chemotherapeutic treatments, have been reported. The reported methods have mostly used HPLC coupled with

fluorescence (Zhou \& Chowbay, 2002), electrochemical (Ricciarello et al., 1998) and chemiluminescence detection (Ahmed et al., 2009).

Moreover, apart from some published LC-MS/MS-based methods with validated quantifications of DOX and/or DOXol in some biological matrices (Sottani, Poggi, Melchiorre, Montagna, \& Minoia, 2013), human plasma (Ibsen et al., 2013), tumors from mice (Liu, Yang, Liu, \& Jiang, 2008), rat plasma (Lachâtrea et al., 2000), human serum, less attention was paid so far for analysis of DOX and its 13-hydroxy metabolite in mouse tissue samples suitable to study the tissue distribution profile of nanoparticle-delivered DOX (Arnold, Slack, \& Straubinger, 2004; Cao \& Bae, 2012; Park et al., 2006). In the present study, a simple, fast and inexpensive HPLC method with MS-MS detection has been developed and validated for quantification of DOX and DOXol in mice biomatrices to obtain a powerful tool for drug distribution evaluation in pharmaceutical research. The method was applied to investigate in BALB/c tumor-bearing mice the bioavailability and biodistribution of DOX, differently formulated, and its reduced metabolite, DOXol. We aimed to study the contribution of different kinds of nano-formulation to improve DOX bioavailability and biodistribution in a murine in vivo tumor model. Moreover, the method can also be applied in therapeutic drug monitoring, a clinical approach used in the optimization of oncologic treatments.

\section{2 | MATERIALS AND METHODS}

\section{1 | Materials}

DOX hydrochloride and the internal standard daunorubicin hydrochloride (DAU) were purchased from Sigma (St. Louis, MO, USA). DOXol trifluoroacetate salt was obtained from AlsaChim (Bioparc, Illkirch, France). The HPLC grade solvents were purchased from Sigma.

\subsection{Control plasma, urine and mouse tissues collection}

Control human plasma and urine samples used for purification and extraction studies and for validation experiments were obtained from healthy volunteers. Blood was collected into a vial containing $\mathrm{K}^{+}$EDTA, which was immediately centrifuged. Aliquots of $15 \mathrm{~mL}$ of pooled plasma were stored at $-80^{\circ} \mathrm{C}$. Human urine, obtained from volunteer colleagues, was collected after a circadian cycle and aliquots of $15 \mathrm{~mL}$ of pooled urine were stored at $-80^{\circ} \mathrm{C}$.

Kidney and liver tissues used for purification and extraction studies and for validation experiments were obtained from healthy $\mathrm{BALB} / \mathrm{c}$ mice.

The tumor tissue samples used in this study have been obtained from an orthotopic model of murine breast cancer. The tumors were generated by injecting in to the mammary fat pad of 8-week-old BALB/c females $1 \times 10^{5} 4 \mathrm{~T} 1$-Luc cells (Bioware-Ultra 4T1-Luc2 cell line; PerkinElmer). 4 T1-Luc is a murine cell line stably transfected with luciferase, which generates a very aggressive breast cancer. The tumors were allowed to grow for 10 days, at which time they reached a size of approximately $0.8 \mathrm{~cm}^{3}$. Mice were killed and organs were explanted, weighted, transferred in a polypropylene plastic Eppendorf tubes, immediately frozen by liquid nitrogen immersion and stored at $-80^{\circ} \mathrm{C}$. Before extraction, whole organs were homogenized in water $(10 \% \mathrm{w} / \mathrm{v})$ with potter (Glas-Col homogenizer) and divided in aliquots of $200 \mu \mathrm{L}$.

\section{3 | Preparation of standard solutions, calibration standards and quality control samples}

Stock solutions of DOX and DOXol were separately prepared in methanol at a concentration of $1 \mathrm{mg} / \mathrm{mL}$ from powder. Even DAU (internal standard) stock solution was prepared in methanol from powder at concentration of $1 \mathrm{mg} / \mathrm{mL}$. Three working solutions containing the mixture of DOX and DOXol at concentrations of $10 \mu \mathrm{g} / \mathrm{mL}, 1 \mu \mathrm{g} / \mathrm{mL}$ and $100 \mathrm{ng} / \mathrm{mL}$, were prepared in methanol mixing and diluting first stock solutions at $1 \mathrm{mg} / \mathrm{mL}$. Similarly, the DAU working solution was prepared in methanol at a concentration of $100 \mathrm{ng} / \mathrm{mL}$ by diluting the first stock solution. Aliquots of first stock solutions and second stock solutions were stored at $-80^{\circ} \mathrm{C}$ while the aliquot in use was stored at $-20^{\circ} \mathrm{C}$.

Calibration standard (CS) samples were prepared in plasma, liver, kidney and tumor tissue homogenates $(0.2 \mathrm{~mL}$ of homogenate $10 \%$ $w / v$ in water) by adding different volumes of the second stock solutions of mixed DOX and DOXol to reach final concentrations of 1.25 , 2.5, 5, 10, 25, 50, 100, 250 and $500 \mathrm{ng} / \mathrm{mL}$. Each solution was spiked with DAU internal standard solution (DAU $1 \mu \mathrm{g} / \mathrm{mL}$, and $100 \mathrm{ng} / \mathrm{mL}$ final concentration). CS for DOX and DOXol quantification in urine samples were prepared in $0.1 \mathrm{~mL}$ of human urine by adding different volumes of the second stock solutions of mixed DOX and DOXol to reach final concentrations of 25, 50, 100, 250, 500, 750 and $1000 \mathrm{ng} / \mathrm{mL}$. Each solution was spiked with DAU as previously described for other biomatrices.

Quality control (QC) samples were prepared in plasma, liver, kidney and tumor tissue homogenates $(0.2 \mathrm{~mL}$ of homogenate $10 \% \mathrm{w} / \mathrm{v}$ in water). Each sample was spiked with different volumes of the second stock solutions of mixed DOX and DOXol at low (LQC), medium (MQC) and high (HQC) concentration levels (5, 25 and $100 \mathrm{ng} / \mathrm{mL}$ for DOX and 1.25, 5 and $25 \mathrm{ng} / \mathrm{mL}$ for DOXol) and with the second stock solution of DAU. QC samples for validation in urine $(0.1 \mathrm{~mL})$ were prepared spiking different volumes of second stock solutions of mixed DOX and DOXol at LQC, MQC and HQC concentration levels (50, 250 and $750 \mathrm{ng} / \mathrm{mL}$ ) and a second stock solution of DAU. 
Pooled plasma or urine used for validation experiments were prepared combining 30 different samples derived from healthy volunteers.

All CS and QC samples were extracted as described below and immediately injected or stored at $-80^{\circ} \mathrm{C}$ until the injection.

Liquid-liquid extraction (LLE) methods commonly used for drug extractions from human plasma or tissue have been assessed. LLE were performed in $15 \mathrm{~mL}$ glass tubes. Different aqueous solutions in combination with different organic phases have been tested. Aqueous solutions were sodium borate solution $(\mathrm{pH} 9)$, acetate buffer ( $\mathrm{pH}$ ), $\mathrm{KOH} 1 \mathrm{M}$ and $\mathrm{H}_{2} \mathrm{SO}_{4} 1 \mathrm{mM}$ whereas the organic solutions were acetonitrile/methyl alcohol 70: 30, chloroform/isopropyl alcohol 50: 50, hexane/ethyl acetate 50: 50, hexane/ethyl acetate 90: 10, chloroform/heptane/isopropyl alcohol 50: 33: 17, dichloromethane/isopropyl alcohol 80: 20 and chloroform/acetone 50: 50. In addition, homogenization of solid tissues directly in acetonitrile/ methyl alcohol 70: 30 has been tested. Comparing all the extraction methods that were tested, the combination of $\mathrm{H}_{2} \mathrm{SO}_{4}$ and chloroform/isopropyl alcohol, as the organic phase, gave better extraction yields. Consequently, CS and real samples were extracted in the following way: $50 \mu \mathrm{L}$ of plasma, or $25 \mu \mathrm{L}$ of urine or $200 \mu \mathrm{L}$ of tissue homogenates $(10 \%$ in water $w / v)$, spiked with DAU, diluted to $1 \mathrm{~mL}$ with $\mathrm{H}_{2} \mathrm{SO}_{4} 1 \mathrm{mM}$ and extracted with chloroform/isopropyl alcohol 50: 50. After organic phase evaporation, the residual was dissolved in $50 \mu \mathrm{L}$ of the initial mobile phase (water/ acetonitrile, 95: $5 \mathrm{v} / \mathrm{v}$ ) and $20 \mu \mathrm{L}$ were injected in to the HPLC for analysis.

\section{4 | HPLC-MS/MS analysis}

The LC system was composed by a Dionex Ultimate 3000 Rapid Separation LC system (DionexThermo Fischer, Rodano Milanese, Italy). Mass analyses were performed on a ABSciex 4000 Q-trap LC-MS/ MS system ( $A B$ Sciex, Foster City, CA, USA). Ionization of analytes was performed using electrospray ionization in a positive mode; the ion source temperature was $550^{\circ} \mathrm{C}$, ion spray voltage was $5500 \mathrm{~V}$ and declustering potential was $62 \mathrm{~V}$ for DOX, DOXol and DAU. Direct infusion and flow injection analysis of DOX, DOXol and DAU made it possible to optimize the MS parameters for fragmentation in a multiple reaction monitoring mode.

Separation of the analytes was carried out on a Phenomenex Gemini C18 column $(150 \mathrm{~mm} \times 2 \mathrm{~mm}$ ID 3$)$ at a flow rate of $0.350 \mathrm{~mL} / \mathrm{min}$. Mobile phase A was ammonium formate $10 \mathrm{mM}$, daily prepared by means of a Milli-Q Synthesis A10 System (Millipore, Billerica, MA, USA), containing $0.1 \% v / v$ formic acid and mobile phase $B$ was acetonitrile. Several gradients of mobile phase A and B have been tested for the chromatographic separation and the following gradient has been selected: $0.0-1.0 \mathrm{~min} 5 \% \mathrm{~B} ; 1.0-3.0 \mathrm{~min}$ to $90 \% \mathrm{~B}$; 3.0-5.0 min to $95 \% \mathrm{~B} ; 5.0-6.0 \mathrm{~min} 95 \% \mathrm{~B} ; 6.0-6.1 \mathrm{~min}$ to $5 \% \mathrm{~B}$; and $6.1-8.5 \mathrm{~min} 5 \% \mathrm{~B}$. The retention times obtained in a total run of T1 8.5 min, comprising re-equilibration at $5 \% \mathrm{~B}$, are listed in Table 1. A representative HPLC-MS/MS analysis of a mouse plasma sample is F1 reported in Figure 1. Quantifications were performed using Multiquant 1.2.1 software by AB Sciex.
TABLE 1 Multiple reaction monitoring transitions ( $\mathrm{m} / \mathrm{z}$ values), CE (eV) and RT (min) used to identify and quantify analytes

\begin{tabular}{|lccccc}
\hline Compound & Mass & Precursor & Product & CE & RT \\
\hline Doxorubicin & 543.52 & 544.2 & $397.5^{\mathrm{a}}$ & 19 & 4.49 \\
& & & $361.5^{\mathrm{a}}$ & 24 & \\
& & & 355.5 & 24 & \\
& & & 130.0 & 38 & \\
\hline Doxorubicinol & 545.54 & 546.2 & $399.5^{\mathrm{a}}$ & 21 & 4.43 \\
& & & $363.5^{\mathrm{a}}$ & 35 & \\
& & & 130.0 & 30 & \\
\hline Daunorubicin & 527.52 & 528.2 & $363.5^{\mathrm{a}}$ & 21 & 4.54 \\
hydrochloride & & & & & \\
\hline
\end{tabular}

$\mathrm{CE}$, collision energy; RT, retention times.

aproduct ions used for quantification.

\section{5 | Validation}

The analytical method was validated to meet the acceptance criteria of the US Food \& Drug Administration guidelines (US Department of Q8 Health and Human Services, Food and Drug Administration, Center for Drug Evaluation and Research, CDER, 2001). Important parameters such as linearity, accuracy, precision, sensitivity (limits of detection [LODs] and limits of quantification [LOQs]), specificity, recovery, stability and influence of matrix effects were determined using plasma, urine and tissue samples.

\section{6 | Selectivity, carry-over and sensitivity}

To exclude any interference or false positive response derived from extractive procedure, reagents or disposable, blank water was extracted according to the method and analyzed in triplicate.

The carry-over was evaluated by analyzing a solvent sample (water/acetonitrile 95: $5 \mathrm{v} / \mathrm{v}$ ) just after the highest CS. The signalnoise ratio of the eventual DOX or DOXol peak in the solvent sample was $<2.5$.

Sensitivity of the method was expressed by LOD and LOQ calculated on calibration curves prepared in plasma, urine, liver, kidney and tumor tissue. LOD and LOQ are expressed respectively as 3.3 and 10 times the ratio between the standard deviation of the response and the slope of the calibration curve (equations 1 and 2). The LOD and LOQ values calculated for all biomatrices are reported in Table 2.

$$
\begin{aligned}
& L O D=3.3 \times \frac{\text { SDav slope }}{\text { Avslope }} \\
& L O Q=10 \times \frac{\text { SDav slope }}{\text { Avslope }}
\end{aligned}
$$

\section{7 | Linearity, precision and accuracy}

The linearity response of analytes was assessed on the five different biomatrices over their respective calibration range from three batches of analytical runs. Different calibration ranges for DOX and DOXol and for different biomatrices have been chosen in relation to 


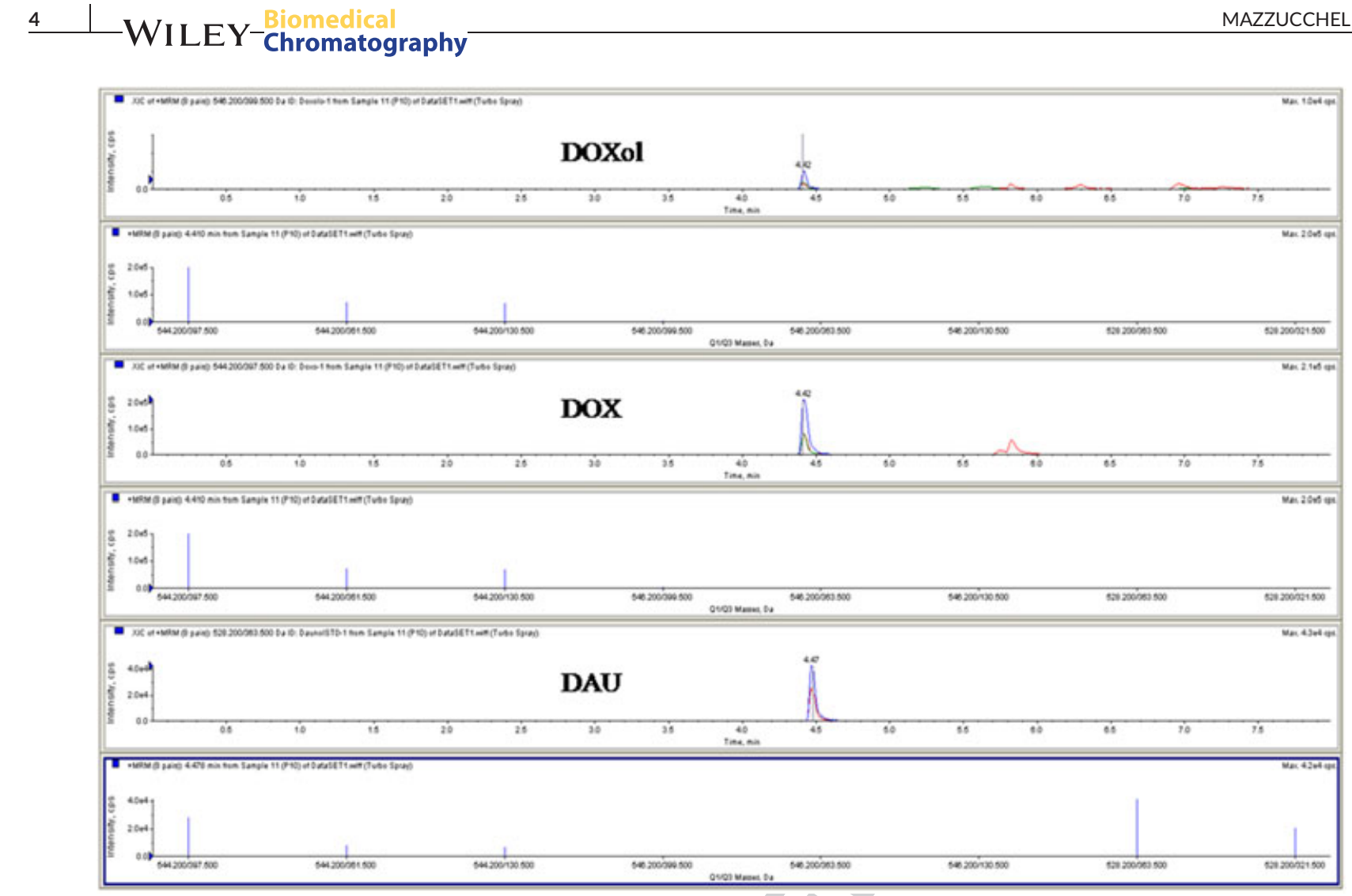

FIGURE 1 HPLC-MS/MS spectra of a real sample of mouse plasma: chromatographic separation and MS/MS analysis of DOX, DOXol and DAU. Q17. DAU, daunorubicin hydrochloride; DOX, doxorubicin; DOXol, doxorubicinol; MRM, multiple reaction monitoring (mode)

concentrations expected in real samples. CS were prepared in plasma, urine and tissues and extracted in triplicate as described. Twenty microliters of eluates were injected and analyzed. A linear model was used to describe the relationship between analyte concentration and instrument response (analyte peak area/internal standard peak area)

T3 lated (Table 3).

Precision and accuracy were determined by QC analyses at LQC, MQC and HQC concentrations over three batch runs. For each QC, analysis was performed in six replicates on each day. Precision was calculated using equation 3 and is denoted by percentage coefficient of variance $(\% \mathrm{CV})$. Accuracy was calculated using equation 4 , where nominal means theoretical amounts, and is denoted by a percentage relative standard error (\%RSE). The accuracy and precision were required and determination and variation coefficients $\left(r^{2}\right.$ and CV) were calcu-

to be within $\pm 15 \%$ RSE of the nominal concentration and $\leq 15 \%$ CV (Table 4).

$$
\begin{gathered}
\% \mathrm{CV}=\left(\frac{\mathrm{SD}}{\text { Mean }}\right) \times 100 \\
\% \mathrm{RSE}=\left(\frac{\text { Mean-nono min } a l}{\text { nono } \min a l}\right) \times 100
\end{gathered}
$$

\section{8 | Recovery and matrix effect}

To evaluate absolute recovery two sets of samples were prepared in plasma, urine and tissue samples. The pre-extraction spiked QC

TABLE 2 Limit of the assay: LOD (expressed in $\mathrm{ng} / \mathrm{mL}$ ) and LOQ (expressed in $\mathrm{ng} / \mathrm{mL}$ ). Recovery expressed as percentage and matrix effect expressed as percentage of ion suppression

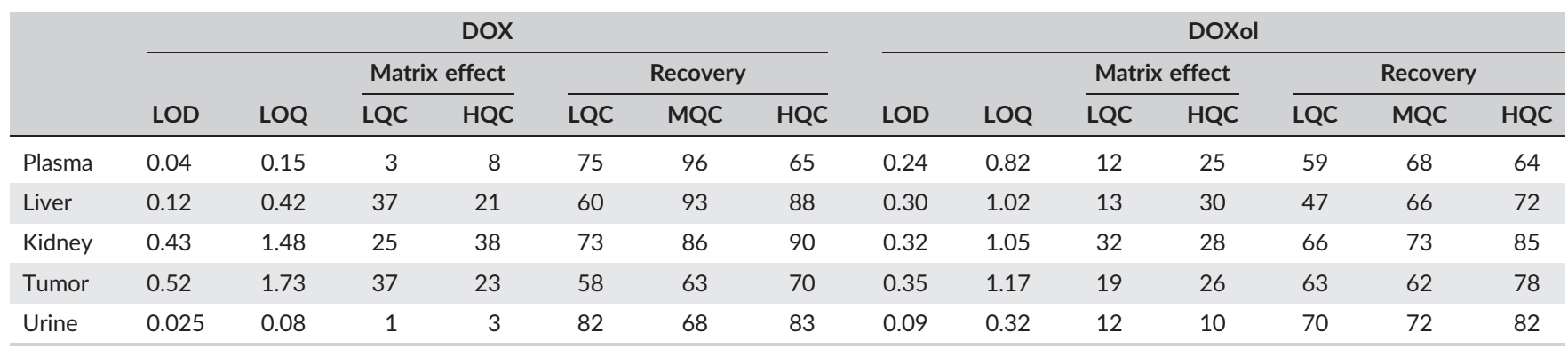

DOX, doxorubicin; DOXol, doxorubicinol; HQC, high quality control; LOD, limit of detection; LOQ, limit of quantification; LQC, low quality control; MQC, medium quality control. 
samples (test samples) were prepared as described at low (DOX $5 \mathrm{ng} /$ $\mathrm{mL}$; DOXol $1.25 \mathrm{ng} / \mathrm{mL}$ ), medium (DOX $25 \mathrm{ng} / \mathrm{mL}$; DOXol $5 \mathrm{ng} / \mathrm{mL}$ ) and high (DOX $100 \mathrm{ng} / \mathrm{mL}$; DOXol $25 \mathrm{ng} / \mathrm{mL}$ ) concentration levels for all matrices except for urine where low, medium and high concentrations were 50,250 and $750 \mathrm{ng} / \mathrm{mL}$ for both DOX and DOXol. For the post-extraction spiked samples (reference samples), aliquots of blank matrices (plasma/urine/liver/kidney/tumor tissue) were processed using the extraction method to yield post-extraction supernatant. Pooled aliquots of post-extraction supernatant were then spiked using DOX and DOXol stock solutions to yield post-extraction samples containing DOX and DOXol at 5-25- and $100 \mathrm{ng} / \mathrm{mL}$ and $1.25-5$ and $25 \mathrm{ng} / \mathrm{mL}$ respectively $(50,250$ and $750 \mathrm{ng} / \mathrm{mL}$ for both Q10 DOX and DOXol for urine). All samples were analyzed sixfold and analyte recovery was determined at each concentration level using the equation 5 where the ratio of the analyte peak areas of the test and reference samples were expressed as a percentage recovery (\%RE). The average \%RE was determined and the calculated precision (CV) did not exceed $15 \%$.

$$
R E=\left(\frac{\text { Peak area of test sample }}{\text { Peak area of reference sample }}\right) \times 100
$$

The presence of suppression or enhancement of the analytical signal was investigated using the post-extraction spike method. Three samples of pooled plasma, urines, liver, kidney and tumor tissue and blank water were extracted following the proposed method. The standards were added to $50 \mu \mathrm{L}$ of eluate at two concentration levels LQC and HQC $(5-250 \mathrm{ng} / \mathrm{mL}$ for different matrices and $25-750 \mathrm{ng} / \mathrm{mL}$ for urine for DOX, and $1.25-25 \mathrm{ng} / \mathrm{mL}$ for different matrices and $25-750 \mathrm{ng} / \mathrm{mL}$ for urine for DOXol). Mean peak areas of standards spiked in eluate from water $\left(A_{w}\right)$ and from biomatrices $\left(A_{p}\right)$ obtained for each concentration were used for calculations (equation 6 ) and results are reported as the ion suppression percentage (Table 2).

$$
\text { Matrix } \quad \text { effect } \%=\left(1-\frac{A_{p}}{A_{w}}\right) \times 100
$$

\section{9 | Sample stability}

Stock solutions stability was established by quantification of samples from dilution of two stock solutions stored at $-80^{\circ} \mathrm{C}$ for 1 month and at room temperature for $6 \mathrm{~h}$. Long-term storage freeze/thaw and bench-top stabilities were determined at LQC and HQC. Long-term storage stability in processed biomatrix was tested up to 40 days upon storage at $-80^{\circ} \mathrm{C}$. Bench-top stability was evaluated from samples kept at room temperature for $15 \mathrm{~h}$ before extraction. Freeze/thaw stability was tested over five cycles of freezing and thawing.

\subsection{Application to real samples}

Tumor-bearing BALB/c mice were anesthetized and injected into the lateral tail vein with DOX, free or encapsulated in ferritin nanoparticles (HFer-DOX) or in liposomes (CAELYX) (1.24 mg kg-1; $n=24$ mice/ group). One, 2, 24 and $48 \mathrm{~h}$ after injection mice were killed ( $n=6$ mice 
TABLE 4 Intra- and interday precision (\%CV) and accuracy (\%RSE) of DOX and DOXol

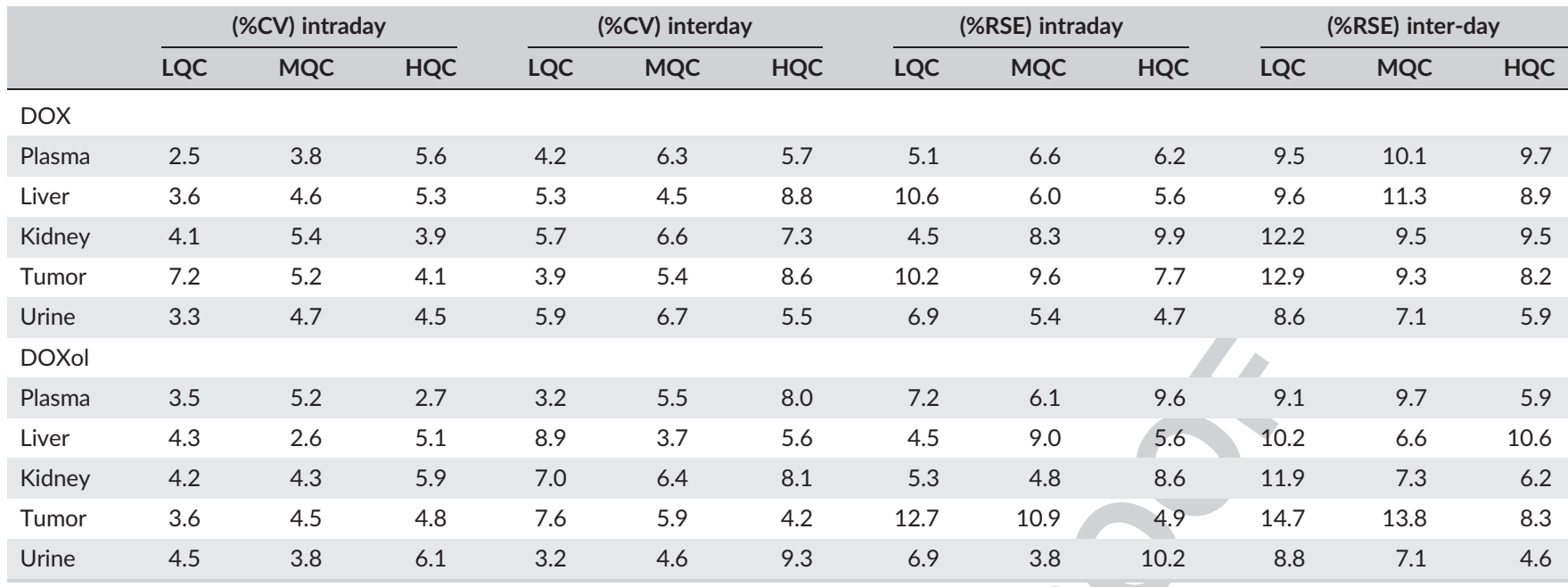

CV, coefficient of variance; DOX, doxorubicin; DOXol, doxorubicinol; HQC, high quality control; LQC, low quality control; MQC, medium quality control; RSE, relative standard error. Q12 211 were collected, weighted, homogenized in water $(10 \% \mathrm{w} / \mathrm{v})$ with potter

(Glas-Col homogenizer), as described above. Mice were used in accordance with an experimental protocol subjected to the direct approval of the Italian Ministry of Health. Aliquots of samples were extracted, analyzed, and DOX and DOXol quantified to investigate the biodistribution of DOX and DOXol, associated to the three different formulations. Results obtained are reported in Figures 2-4.

\subsection{1 | Statistics}

If not otherwise specified, quantitative analyses were performed in triplicate. Calibration curves are expressed as mean \pm SD. For application to real samples, six mice per group were analyzed and each matrix was extracted and analyzed in triplicate. Reported data are expressed as the mean of all analyses performed per group \pm SD.

\section{3 | RESULTS AND DISCUSSION}

The reflection that the reduction of DOX to DOXol involves the addition of only two mass units emphasizes the need for adequate methods for their quantification. There are several analytical methods, including HPLC-MS/MS methods, available for DOX and DOXol determination (Ahmed et al., 2009; Ibsen et al., 2013; Lachâtrea et al., 2000; Liu et al., 2008; Ricciarello et al., 1998; Sottani et al., 2013; Zhou \& Chowbay, 2002). However, most of them have disadvantages, such as long analytical run time (16 min; Sottani et al., 2013) or (21 min; Ibsen et al., 2013), or complex and expensive extraction procedures, solid phase extraction procedure on expensive OASIS HBL (Ibsen et al., 2013; Lachâtrea et al., 2000; Liu et al., 2008; Sottani et al., 2013). Moreover, the majority of published methods are focused on quantifications of DOX and some of its metabolites in plasma matrix using at least $100 \mu \mathrm{L}$ of the sample (Lachâtrea et al., 2000; Liu et al., 2008; Sottani et al., 2013), but unfortunately these quantities are too large for the application in pharmacological studies on mouse models. To date, less attention was paid to the analysis of DOX and its metabolite DOXol in mouse tissue samples (Arnold et al., 2004; Cao \& Bae, 2012; Park et al., 2006). In this study, we developed and validated an LC-MS/MS method for simultaneous determination of DOX and DOXol in small amounts of plasma, urine, liver, kidneys and tumor tissue suitable to study the distribution profile of these molecules in the organism after DOX administration. This method will be a powerful tool for drug distribution evaluation in pharmaceutical research to understand better the side effect mechanisms linked to DOX administration.

We selected DAU as internal standard for quantification because it is an analog of DOX with chemical and structural characteristics suitable for this purpose. The use of DAU as the internal standard for DOX and DOXol quantification, indeed, is well documented in the literature (Maudens, Stove, \& Lambert, 2011). Moreover the choice of DAU, less expensive and readily commercially available, instead of the deuterium-labeled DOX makes the method cheap and easily applicable, suitable for pharmacological research but also attractive for drug monitoring. The validation fully performed in the five biomatrices probably helps to overcome possible problems linked to the choice of the internal standard.

The present method, with high sensitivity and specificity, proposes a simple, fast and cheap LLE applicable to a large number of biomatrices. Indeed, the method has been validated on five different biomatrices such as plasma, urine and three different kind of tissues comprising liver, kidneys and tumor tissue, which is more difficult to homogenize and extract due to its fibrous characteristic. Moreover, DOX and DOXol quantification in samples from mice treated with free DOX, CAELYX or HFer-DOX, have been used as a preliminary study to investigate their biodistribution profiles to evaluate the differences associated to the nano-formulations, demonstrated the applicability of the method to real samples (Figures 2 and 3).

\subsection{Extraction procedure and analytic conditions}

LLE was examined using different organic solvents such as dichloromethane, ethyl acetate, chloroform, hexane and isopropyl alcohol with different acidic and basic aqueous solutions. 

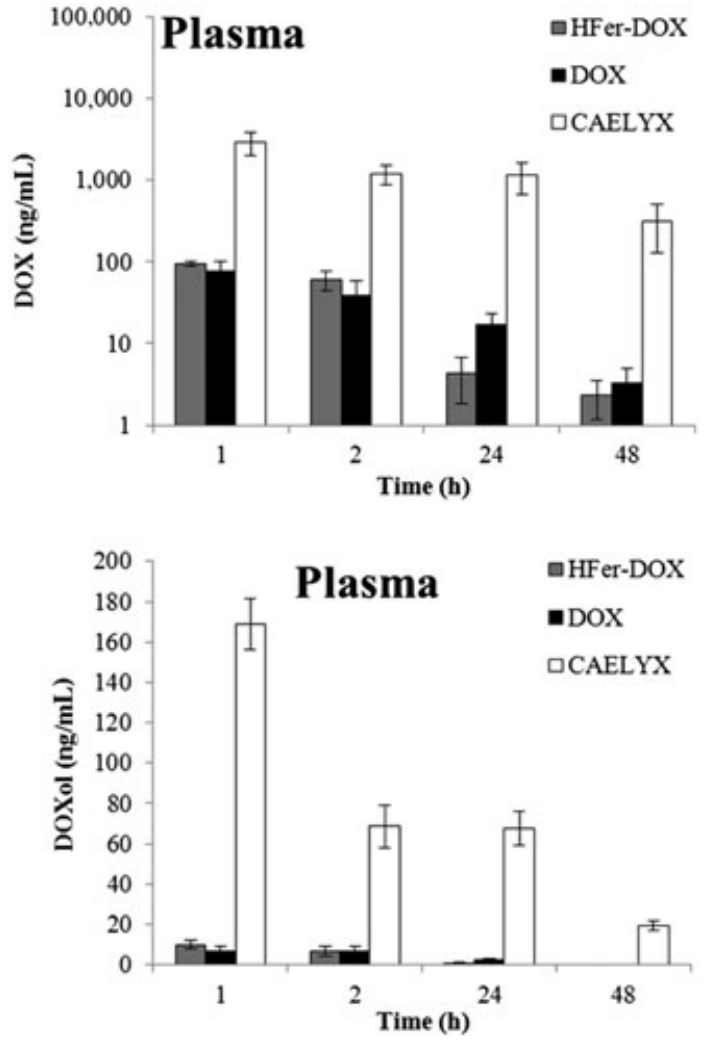

FIGURE 2 Bioavailability of free DOX in comparison with liposomal (CAELYX) and ferritin nano-formulated DOX (HFer-DOX) at different time points. Female BALB/c mice orthotopically implanted with $4 \mathrm{T1}-\mathrm{L}$ murine mammary carcinoma cells were injected 6 days after implantation (time 0) with free DOX (black), CAELYX (white) and HFer-DOX (gray) $1.24 \mathrm{mg} / \mathrm{kg}$. DOX and DOXol levels in plasma have been determined 1,2, 24 and $48 \mathrm{~h}$ after intravenous injection following acidified isopropanol extraction from tumor homogenates. Aliquots from six mice per each time point concentration have been extracted in duplicate and analyzed by HPLC/MS/MS. Reported values are means of six samples/group in duplicate \pm SE. DOX, doxorubicin; DOXol, doxorubicinol

The protocol where the acidic dilution of the sample $\left(\mathrm{H}_{2} \mathrm{SO}_{4} 1 \mathrm{mM}\right.$ in water) was combined with chloroform/isopropyl alcohol (50: $50 \mathrm{v} / \mathrm{v}$ ) was found to provide very good extraction yields of the two compounds (i.e. DOX and DOXol) displaying a clean chromatogram. Furthermore, the same LLE method can be applied to a large number of different biomatrices as plasma and urine and different tissues such as liver, kidney and tumor with good results in terms of recovery and chromatogram quality. Direct extraction with organic solvent, indeed, gave worst chromatograms leading to less sensibility. At the same time, the pre-dilution with sodium borate solution or acetate or $\mathrm{KOH}$ gave a substantial decrease in recovery. Moreover, the selected extraction is fast and cheap allowing easy management of a large number of samples, as generally happens in therapeutic drug monitoring.

\section{2 | HPLC-MS/MS analysis}

The development of the HPLC-MS/MS method started with optimization of MS ionization and fragmentation of both the analytes and internal standard (DOX, DOXol and DAU; each $100 \mathrm{ng} / \mathrm{mL}$ ) via infusion into the electrospray source in positive and negative ionization mode. A positive ionization mode exhibited a better response than that in negative mode.
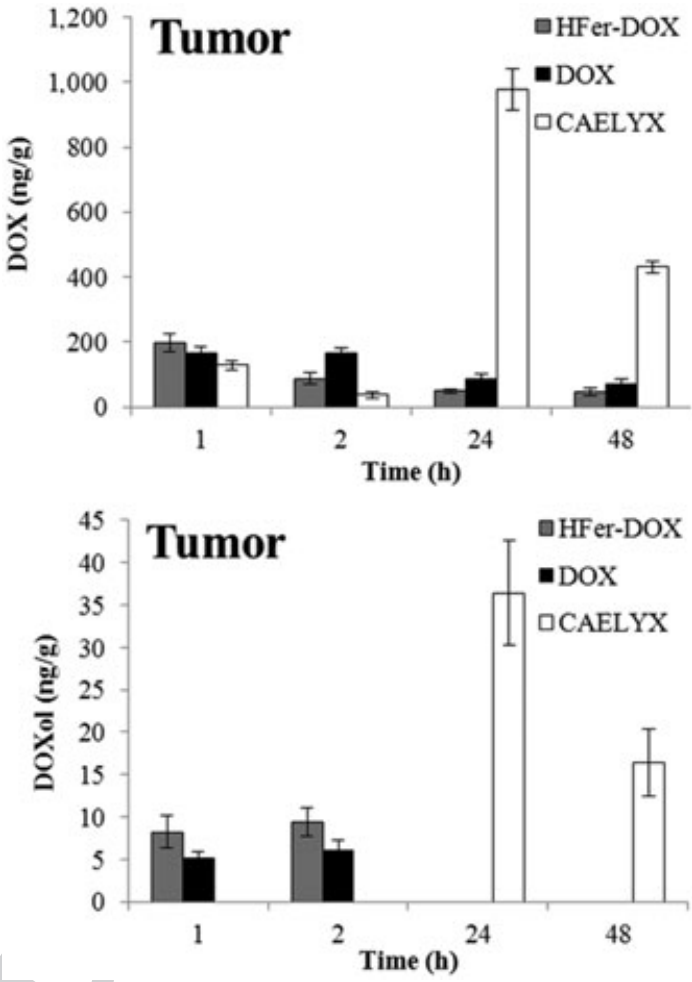

FIGURE 3 DOX and DOXol accumulation at 4 T1-L tumor in mice at different time points after administration of $1.24 \mathrm{mg} / \mathrm{kg}$ of free DOX (black), CAELYX (white) and HFer-DOX (gray). Female BALB/c mice orthotopically implanted with $4 \mathrm{~T} 1-\mathrm{L}$ murine mammary carcinoma cells were injected 6 days after implantation (time 0) with DOX or HFnDOX. DOX levels in tumors have been determined 1, 2, 24 and $48 \mathrm{~h}$ after intravenous injection following acidified isopropanol extraction from tumor homogenates. Aliquots from six mice per each time point concentration have been extracted in duplicate and analyzed by $\mathrm{HPLC} / \mathrm{MS} / \mathrm{MS}$. Reported values are means of six samples/group in duplicate \pm SE. DOX, doxorubicin; DOXol, doxorubicinol

The protonated precursor ions $\mathrm{m} / \mathrm{z} 544.2[\mathrm{M}+\mathrm{H}]^{+}, 546.2[\mathrm{M}+\mathrm{H}]^{+}$ and $528.2[\mathrm{M}+\mathrm{H}]^{+}$generated product ions $\mathrm{m} / \mathrm{z} 397.5,361.5,355.5$ and $130.0,399.5,363.5$ and $130.0,363.5$ and 321.5 , by collisioninduced dissociation for DOX, DOXol and DAU, respectively (Table 1). Using multiple reaction monitoring analyses collision energy was varied from 0 to $60 \mathrm{eV}$ and adjusted for DOX, DOXol and DAU to maximize product ion formation of transitions selected for quantification $(\mathrm{m} / \mathrm{z} 397.5$ and 361.5 for DOX, 399.5 and 363.5 for DOXol, and 363.5 for DAU). Figure 1 reported MS/MS spectra of analytes along with the chromatographic separation of DOX DOXol and DAU in a mouse plasma sample. The obtained chromatographic separation was satisfactory between DOX, DOXol and DAU using a short run time and the use of an MS/MS technique on a triple quadrupole, Q1406 with an $\mathrm{m} / \mathrm{z}$ interval of 0.5 on the first quadrupole, which meant it was possible to overcome the possible loss in accuracy due to the selection of the product ion $\mathrm{m} / \mathrm{z} 363.5$ for quantification of both DOXol and DAU. Therefore, various mobile phase compositions with a different $\mathrm{pH}$ value, column and flow rate were tried. Reverse phase HPLC column exhibited best sensitivity, efficiency and peak shape with a gradient of acetonitrile and ammonium formate $10 \mathrm{mM}(0.1 \%$ formic acid) as mobile phases, at a flow rate of $0.35 \mathrm{~mL} / \mathrm{min}$. The 

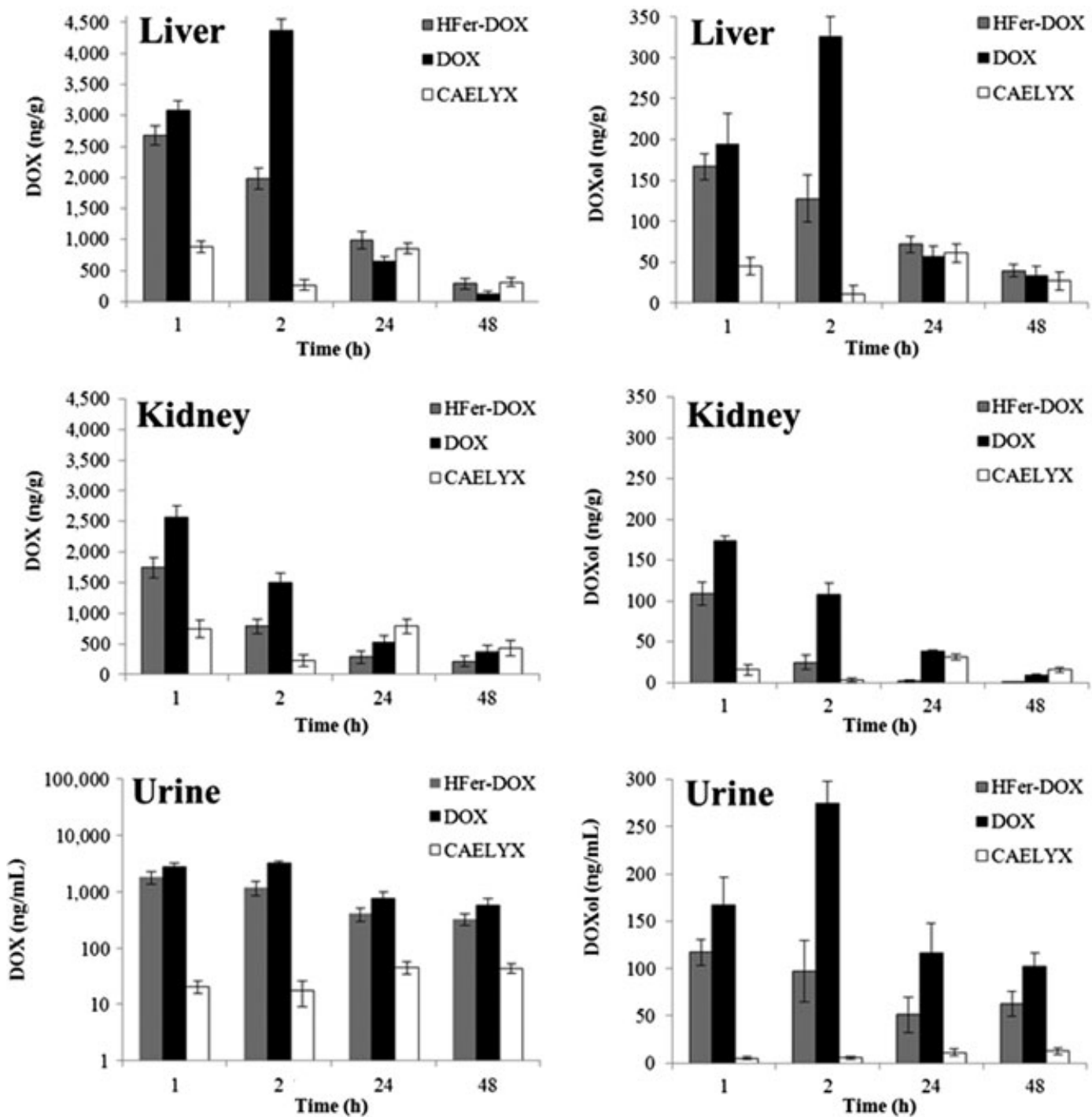

FIGURE 4 Biodistribution of DOX and DOXol upon single administration of $1.24 \mathrm{mg} / \mathrm{kg}$ of free DOX (black), CAELYX (white) and HFer-DOX (gray). Tumor-bearing mice ( $n=24$ /group) were treated with HFn-DOX or free DOX. Liver, kidneys and urine were collected at 1, 2, 24 and $48 \mathrm{~h}$ after injection. DOX and DOXol content in each sample were analyzed by HPLC/MS/MS. Reported values are means of six samples/group in duplicate \pm SE. DOX, doxorubicin; DOXol, doxorubicinol

retention times of both the analytes (DOX $4.49 \mathrm{~min}$ and DOXol $4.43 \mathrm{~min}$ ) and DAU (4.54 min) were low enough to allow a short total run time of 8.0 min comprising clearing and reconditioning of the column with the initial mobile phase.

\section{3 | Validation}

The assay was fully validated following the acceptance criteria of the US Food and Drug Administration guidelines to demonstrate the linearity, precision, accuracy, limits of the methods LOQ and LOD, recovery and sample stability by using the CS and QC samples prepared in all five biomatrices.

\subsection{Selectivity, carry-over and sensitivity}

The selection of a specific precursor ion followed by the formation and detection of a specific product ion makes quantitative MS highly specific. All reagents and disposable materials used did not interfere with the revelation and quantification of DOX and DOXol. Biological matrices did not give false positive responses or co-eluting components. No carry-over to analytes from one sample to another was observed.

LOD and LOQ levels have been calculated for plasma, urine and tissues as reported in the experimental part and are listed in Table 1. The LOD range from 0.025 to $0.52 \mathrm{ng} / \mathrm{mL}$ for DOX and 0.09 to $0.35 \mathrm{ng} / \mathrm{mL}$ for DOXol, and the LOQ range from 0.08 to $1.73 \mathrm{ng} / \mathrm{mL}$ for DOX and 0.32 to $1.17 \mathrm{ng} / \mathrm{mL}$ for DOXol. All the assay values were found to be within the accepted variable limits ( $\pm 15 \%$ RSE, $\leq 15 \%$ CV and $\pm 20 \%$ RSE, $\leq 20 \% \mathrm{CV}$ ) (Morin, Taillon, Furtado, \& Garafolo, 2012). The differences between LOD and LOQ values reflect the different complexity of the five matrices. LOD and LOQ values indeed increase with the complexity of matrices from urine to tumor tissue. Despite these differences, the method display a good sensitivity in all assessed matrices. 


\subsection{Linearity, accuracy and precision}

Linear calibration curves, built according to the formula $y=m x+b$, were obtained by plotting the peak area ratio of internal standard versus concentrations of DOX and DOXol. Good linearity $(r>0.99)$ was exhibited over concentration range of $5-250 \mathrm{ng} / \mathrm{mL}$ for DOX and $1.25-25 \mathrm{ng} / \mathrm{mL}$ for DOXol in plasma and tumor, $25-500 \mathrm{ng} / \mathrm{mL}$ for DOX and $1.25-25 \mathrm{ng} / \mathrm{mL}$ for DOXol in kidney and liver, and of $25-1000 \mathrm{ng} / \mathrm{mL}$ for DOX and DOXol in urine (Table 3). These different ranges were selected for the assessed biomatrices to have good calibration curves, for the expected values, useful for DOX and DOXol quantification in real samples from in vivo studies.

Accuracy and precision were assessed by analyzing QC on three different days. Results can be summarized as follows: intraday precision ranges are $2.5-7.2 \%$ for DOX and $2.7-6.1 \%$ for DOXol, interday 3.9-8.8\% for DOX and 3.2-9.3\% for DOXol, intraday and interday accuracy range $4.5-10.2 \%$ for DOX and $3.8-12.7 \%$ for DOXol and 5.9-12.9\% for DOX and 4.6-14.7\% for DOXol respectively (Table 4). Results reported in Table 4 show that interday accuracy in tumor tissue present highest values of \%RSE that are within the accepted limit of $15 \%$.

\subsection{Recovery and matrix effect}

The recovery has been evaluated by the post-extraction method. The mean extraction recovery ratios of DOX and DOXol of QCs are between 58 and $96 \%$ and between 47 and $85 \%$ respectively. $(3.2 \geq \mathrm{CV} \leq 8.6)$.

Matrix effects are reported in Table 4 with recoveries and expressed as the ion suppression percentage that ranges $1-38 \%$ for DOX and $10-32 \%$ for DOXol $(2.9 \geq \mathrm{CV} \leq 10.3)$. As LOD and LOQ even recovery and matrix effect values reflect increasing complexity from urine to tissues.

\section{7 | Sample stability}

Stability of DOX and DOXol in biomatrices was evaluated under a variety of conditions to establish length of storage and sample processing. DOX and DOXol exhibited no significant degradation under previously described conditions. In particular, analytes are stable in biomatrices for $15 \mathrm{~h}$ at room temperature, five freeze-thaw cycles and for 3 days at room temperature (processed samples). Stock solutions are stable at least for 1 month at $-80^{\circ} \mathrm{C}$.

\subsection{Application of the method}

This method has been applied to study the impact of nano-formulation on DOX and DOXol biodistribution. As nano-formulated drugs, we have selected CAELYX and HFer-DOX. The first is a liposomal DOX currently applied in clinical practice, while the last is a very promising nano-formulation of DOX, which until now was investigated in pre-clinical studies. While CAELYX mediates the DOX tumor delivery taking advantage of the enhanced permeability and retention effect, HFer-DOX triggered a tumor-targeted nuclear delivery of drug (Barenholz, 2012; Bellini et al., 2014; Zhang et al., 2015). Tumor-bearing BALB/c mice were treated with free DOX, CAELYX or HFer-DOX (1.24 mg DOX kg-1). One, 2, 24 and $48 \mathrm{~h}$ after intravenous injection into the tail vein, mice $(n=6 /$ experimental group) were killed and plasma, urine, tumor, liver and kidneys were collected. DOX and DOXol were extracted from biological samples and analyzed. Where necessary, plasma of CAELYX-treated mice and urine of HFer-DOX-treated mice were diluted with water (HPLC purity grade) before extraction to obtain concentration included in the linearity range. Liposomal nano-formulation of DOX (i.e. CAELYX) significantly improves drug bioavailability and circulation time in comparison to free DOX and HFer-DOX samples. However, liposomal nano-formulation fails in avoiding the DOX transformation into DOXol, increasing also DOXol bioavailability and circulation time, which may result in high drug toxicity (Figure 2). Time-dependent DOX and DOXol tumor accumulation reported in Figure 3 clearly points out that DOX and HFer-DOX come to tumor quickly reaching the maximum value of drug content between 1 and $2 \mathrm{~h}$ after injection, while CAELYX arrives to cancer slowly, achieving the peak value $24 \mathrm{~h}$ after nanoparticle administration. DOXol accumulation sketchily follows that observed for the profile of DOX, except for the significant contribution of ferritin nanocage/ nano-formulation to enhance tumor accumulation of DOXol in comparison to the free drug. In contrast to tumor samples, both DOX and DOXol showed higher accumulation in off-target organs in DOX-treated mice, suggesting a role of nano-formulation in reducing the capture of DOX and metabolites from liver and kidneys, which may result in lower toxicity (Figure 4). Moreover, urine samples strongly evidenced that the faster tumor accumulation and the short circulation time observed in free DOX and HFer-DOX samples are coupled with a faster washout, which may affect the drug therapeutic index (Figure 4).

\section{4 | CONCLUSIONS}

In conclusion, a selective, sensitive and rapid LC-MS/MS method was developed and validated to determine simultaneously the concentration of DOX and its reduced metabolite DOXol in small volumes of murine plasma, urine and tissue samples. An excellent linearity $\left(R^{2}>0.99\right)$, good accuracy, precision and specificity meeting acceptability criteria according to US Food and Drug Administration guidelines have been demonstrated for the determination of DOX and its 13-hydroxy metabolite, using DAU as the internal standard. Moreover, the simple, quick and cheap extraction procedure, applicable to a large number of biomatrices, and the short chromatographic run time, together with the requirements of very low plasma, urine or tissue samples, render this method particularly attractive for pharmacological research performed on murine animal models. Finally, this method has been applied to measure the biodistribution of DOX and DOXol in the mouse organism after administration of nanoparticles carrying DOX as an antitumor agent, demonstrating it as a powerful tool for pharmaceutical research.

\section{CONFLICT OF INTEREST}

The authors declare no conflict of interest. 
Maudens, K. E., Stove, C. P., \& Lambert, W. E. (2011). Quantitative liquid chromatographic analysis of anthracyclines in biological fluids. Journal of Chromatography B, 879, 2471-2486.

We thank the University of Milan and the Fondazione Regionale per la Ricerca Biomedica (NANODRUG platform project to F.C.) for financial support. FRRB supported S.M. with Research Fellowships.

\section{REFERENCES}

Ahmed, S., Kishikawa, N., Ohyama, K., Wada, M., Nakashima, K., \& Kuroda, N. (2009). Selective determination of doxorubicin and doxorubicinol in rat plasma by HPLC with photosensitization reaction followed by chemiluminescence detection. Talanta, 78, 94-100.

Arnold, R. D., Slack, J. E., \& Straubinger, R. M. (2004). Quantification of Doxorubicin and metabolites in rat plasma and small volume tissue samples by liquid chromatography/electrospray tandem mass spectroscopy. Journal of Chromatography B: Biomedical Sciences and Applications, 808, 141-152.

Barenholz, Y. (2012). Doxil $($-The first FDA-approved nano-drug: Lessons learned. Journal of Controlled Release, 160, 117-134.

Bellini, M., Mazzucchelli, S., Galbiati, E., Sommaruga, S., Fiandra, L., Truffi, M., ... Prosperi, D. (2014). Protein nanocages for self-triggered nuclear delivery of DNA-targeted chemotherapeutics in Cancer Cells. Journal of Controlled Release, 196, 184-196.

Cao, P., \& Bae, Y. (2012). Comparison between microplate spectrometry and LC/MS chromatography for facile pilot pharmacokinetics and biodistribution studies of doxorubicin-loaded nanoparticle drug carriers. Journal of Applied Pharmacological Science, 2, 21-29.

Duggan, S. T., \& Keating, G. M. (2011). Pegylated liposomal doxorubicin. Drugs, 71, 2531-2558.

Ho, J. A., Fan, N., Jou, A. F., Wu, L., \& Sun, T. (2012). Monitoring the subcellular localization of doxorubicin in CHO-K1 using MEKC-LIF: liposomal carrier for enhanced drug delivery. Talanta, 99, 683-688.

Ibsen, S., Su, Y., Norton, J., Zahavy, E., Hayashi, T., Adams, S., ... Esener, S. J. (2013). Extraction protocol and mass spectrometry method for quantification of doxorubicin released locally from prodrugs in tumor tissue. Journal of Mass Spectrometry, 48, 768-773.

Lachâtrea, F., Marqueta, P., Ragota, S., Gauliera, J. M., Cardotb, P., \& Dupuya, J. L. (2000). Simultaneous determination of four anthracyclines and three metabolites in human serum by liquid chromatographyelectrospray mass spectrometry. Journal of Chromatography B: Biomedical Sciences and Applications, 738, 281-291.

Lianga, M., Fana, K., Zhoua, M., Duana, D., Zhenga, J., Yanga, D., ... Yana, X. (2014). H-ferritin-nanocaged doxorubicin nanoparticles specifically target and kill tumors with a single-dose injection. Proceedings of the National Academy of Sciences USA, 11, 14900-14905.

Liu, Y., Yang, Y., Liu, X., \& Jiang, T. (2008). Quantification of PEGylated liposomal doxorubicin and doxorubicinol in rat plasma by liquid chromatography/electrospray tandem mass spectroscopy: Application to preclinical pharmacokinetic studies. Talanta, 74, 887-895.
Morin, L. P., Taillon, M. P., Furtado, M., \& Garafolo, F. (2012). An alternative solution to over-come carryover issues in bioanalysis. Bioanalysis, 4 , 133-141.

Park, J. P., Fong, M., Lu, J., Russell, K. S., Booth, C. J., Saltzman, W. M., \& Fahmy, T. M. (2009). PEGylated PLGA nanoparticles for the improved delivery of doxorubicin. Nanomedicine: Nanotechnology, Biology and Medicine, 5, 410-418.

Park, J.-S., Kim, H.-K., Lee, H.-W., Lee, M.-H., Kim, H.-G., Chae, S.-W., \& Chae, H.-J. (2006). Validation of a HPLC MS/MS method for determination of doxorubicin in mouse serum and its small tissues. Korean Journal of Clinical Pharmacology, 16, 23-27.

Rao, W., Wang, H., Han, J., Zhao, S., Dumbleton, J., Agarwal, P., ... He, X. (2015). Chitosan-decorated doxorubicin-encapsulated nanoparticle targets and eliminates tumor reinitiating cancer stem-like cells. ACS Nano, 9, 5725-5740.

Ricciarello, R., Pichini, S., Pacifici, R., Altieri, I., Pellegrini, M., Fattorossi, A., \& Zuccaro, P. (1998). Simultaneous determination of epirubicin, doxorubicin and their principal metabolites in human plasma by highperformance liquid chromatography and electrochemical detection. 707, 219-225.

Sottani, C., Poggi, G., Melchiorre, F., Montagna, B., \& Minoia, C. (2013). Simultaneous measurement of doxorubicin and reduced metabolite doxorubicinol by UHPLC-MS/MS in human plasma of HCC patients treated with TACE. Journal of Chromatography B: Biomedical Sciences and Applications, 915-916, 71-78.

US Department of Health and Human Services, Food and Drug Administration, Center for Drug Evaluation and Research (CDER). (2001). Guidance for Industry, Bioanalytical Method Validation, 2001. Guidance for Industry: Bioanalytical Method Validations. http://www.fda. ov/downloads/Drugs/Guidances/ucm070107

Zhang, L., Li, L., Di Penta, A., Carmona, U., Yang, F., Schöps, R., ... Knez, M. (2015). H-ChainFerritin: A natural nuclei targeting and bioactive delivery nanovector. Advanced Health Material, 4, 1305-1310.

Zhou, Q. Y., \& Chowbay, B. (2002). Determination of doxorubicin and its metabolites in rat serum and bile by LC: application to preclinical pharmacokinetic studies. Journal of Pharmaceutical and Biomedical Analysis, 30, 1063-1074.

How to cite this article: Mazzucchelli, S., Ravelli, A., Gigli, F., Minoli, M., Corsi, F., Ciuffreda, P., and Ottria, R. (2016), LC$\mathrm{MS} / \mathrm{MS}$ method development for quantification of doxorubicin and its metabolite 13-hydroxy doxorubicin in mice biological matrices: application to a pharmaco-delivery study. Biomedical Chromatography, doi: 10.1002/bmc.3863 Journal of Chromatography B: Biomedical Sciences and Applications, 


\section{Author Query Form}

\section{Journal: Biomedical Chromatography}

\section{Article: bmc_3863}

Dear Author,

During the copyediting of your paper, the following queries arose. Please respond to these by annotating your proofs with the necessary changes/additions.

- If you intend to annotate your proof electronically, please refer to the E-annotation guidelines.

- If you intend to annotate your proof by means of hard-copy mark-up, please use the standard proofing marks. If manually writing corrections on your proof and returning it by fax, do not write too close to the edge of the paper. Please remember that illegible mark-ups may delay publication.

Whether you opt for hard-copy or electronic annotation of your proofs, we recommend that you provide additional clarification of answers to queries by entering your answers on the query sheet, in addition to the text mark-up.

\begin{tabular}{|c|c|c|}
\hline Query No. & Query & Remark \\
\hline Q1 & $\begin{array}{l}\text { AUTHOR: Please confirm that given names (red) and surnames/family names (green) } \\
\text { have been identified correctly. }\end{array}$ & \\
\hline Q2 & $\begin{array}{l}\text { AUTHOR: The citation "Duggan et al., } 2011 \text { " has been changed to "Duggan and } \\
\text { Keating, 2011" to match the author name/date in the reference list. Please check if } \\
\text { the change is fine in this occurrence and modify the subsequent occurrences, if } \\
\text { necessary. }\end{array}$ & \\
\hline Q3 & $\begin{array}{l}\text { AUTHOR: The citation "Zhou et al., 2002" has been changed to "Zhou and Chowbay, } \\
2002 \text { " to match the author name/date in the reference list. Please check if the change is } \\
\text { fine in this occurrence and modify the subsequent occurrences, if necessary. }\end{array}$ & \\
\hline Q4 & $\begin{array}{l}\text { AUTHOR: The citation "Cao et al., 2012" has been changed to "Cao and Bae, 2012" to } \\
\text { match the author name/date in the reference list. Please check if the change is fine in this } \\
\text { occurrence and modify the subsequent occurrences, if necessary. }\end{array}$ & \\
\hline Q5 & AUTHOR: PerkinElmer—pls add address & \\
\hline Q6 & AUTHOR: potter-what is this? & \\
\hline Q7 & AUTHOR: All CS and QC samples-OK now (was 'All CS and QS samples')? & \\
\hline Q8 & $\begin{array}{l}\text { AUTHOR: The citation "US Department of Health and Human Services, 2001" has } \\
\text { been changed to "US Department of Health and Human Services, Food and Drug } \\
\text { Administration, Center for Drug Evaluation and Research, CDER, 2001" to match the } \\
\text { author name/date in the reference list. Please check if the change is fine in this } \\
\text { occurrence and modify the subsequent occurrences, if necessary. }\end{array}$ & \\
\hline Q9 & $\begin{array}{l}\text { AUTHOR: To exclude any interference or false positive response derived from } \\
\text { extractive procedure, reagents or disposable, blank water was extracted according to } \\
\text { the method-is this the method described above? }\end{array}$ & \\
\hline Q10 & $\begin{array}{l}\text { AUTHOR: to yield post-extraction samples containing DOX and DOXol at } 5-25 \text { and } \\
100 \mathrm{ng} / \mathrm{mL} \text { and } 1.25-5 \text { and } 25 \mathrm{ng} / \mathrm{mL} \text { respectively-OK or should this be 'to yield } \\
\text { post-extraction samples containing DOX and DOXol at } 5,25 \text { and } 100 \mathrm{ng} / \mathrm{mL} \text { and } \\
1.25,5 \text { and } 25 \mathrm{ng} / \mathrm{mL} \text { respectively'? }\end{array}$ & \\
\hline Q11 & $\begin{array}{l}\text { AUTHOR: Organs were collected, weighted, homogenized in water-OK or should } \\
\text { 'weighted' be 'weighed' here? }\end{array}$ & \\
\hline Q12 & AUTHOR: potter-what is this? & \\
\hline
\end{tabular}




\begin{tabular}{|c|l|c|}
\hline Query No. & \multicolumn{1}{|c|}{ Query } \\
\hline Q13 & AUTHOR: OASIS HBL-what is this? \\
\hline Q14 & $\begin{array}{l}\text { AUTHOR: The obtained chromatographic separation was satisfactory between DOX, } \\
\text { DOXol and DAU using a short run time_OK now? }\end{array}$ \\
\hline Q15 & $\begin{array}{l}\text { AUTHOR: limits of the methods LOQ and LOD—-does this make sense? Should it just } \\
\text { be 'LOQ and LOD methods'? }\end{array}$ \\
\hline Q16 & $\begin{array}{l}\text { AUTHOR: As LOD and LOQ even recovery and matrix effect values reflect increasing } \\
\text { complexity from urine to tissues. - does this make sense? }\end{array}$ \\
\hline Q17 & AUTHOR: Figure 1 contains poor quality of text. Please resupply if necessary. \\
\hline
\end{tabular}


Required software to e-Annotate PDFs: Adobe Acrobat Professional or Adobe Reader (version 7.0 or above). (Note that this document uses screenshots from Adobe Reader $\mathrm{X}$ )

The latest version of Acrobat Reader can be downloaded for free at: http://get.adobe.com/uk/reader/

Once you have Acrobat Reader open on your computer, click on the Comment tab at the right of the toolbar:

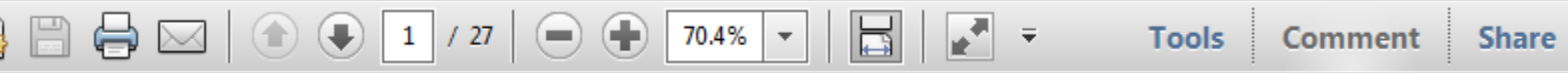

This will open up a panel down the right side of the document. The majority of tools you will use for annotating your proof will be in the Annotations section, pictured opposite. We've picked out some of these tools below:

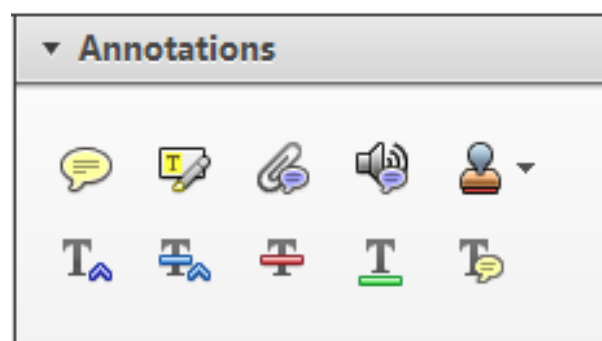

1. Replace (Ins) Tool - for replacing text.

Strikes a line through text and opens up a text box where replacement text can be entered.

How to use it

- Highlight a word or sentence.

- Click on the Replace (Ins) icon in the Annotations section.

- Type the replacement text into the blue box that appears.

Idard tramework for the analysis of $\mathrm{m}$ icy-Nevertheless, it also led to exog،

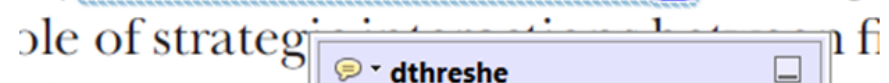
aber of comp 08/06/2011 15:58:17 is that the s1 nain compo: be level, are exc nc

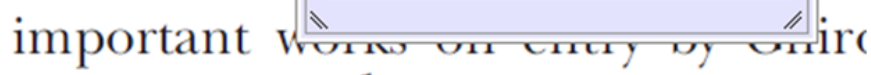
M heneferth) ${ }^{1}$ we anen the "hlarl $\mathrm{l}$

3. Add note to text Tool - for highlighting a section to be changed to bold or italic.

T Highlights text in yellow and opens up a text box where comments can be entered.

\section{How to use it}

- Highlight the relevant section of text.

- Click on the Add note to text icon in the Annotations section.

- Type instruction on what should be changed regarding the text into the yellow box that appears.

namic responses of mark ups ent with the VAR evidence

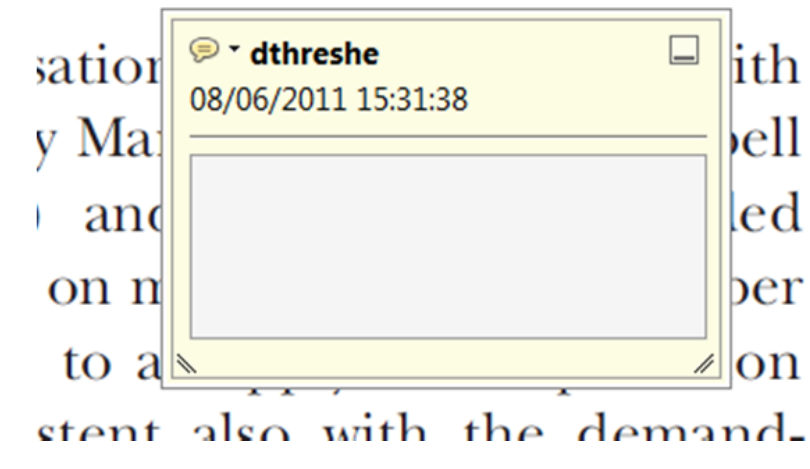

2. Strikethrough (Del) Tool - for deleting text.

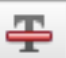

Strikes a red line through text that is to be deleted.

How to use it

- Highlight a word or sentence.

- Click on the Strikethrough (Del) icon in the Annotations section.

there is no room tor extra prohts al c ups are zero and the number of ret) values are not determined by Blanchard and Kiyotaki (1987), sfect competition in general equilil ts of aggregate demand and supply lassical framework assuming monol eph on evorenous number of firme

4. Add sticky note Tool - for making notes at specific points in the text.

Marks a point in the proof where a comment needs to be highlighted.

How to use it

- Click on the Add sticky note icon in the Annotations section.

- Click at the point in the proof where the comment should be inserted.

- Type the comment into the yellow box that appears.

iaisu airu suppiy sirucks. hivsl ui

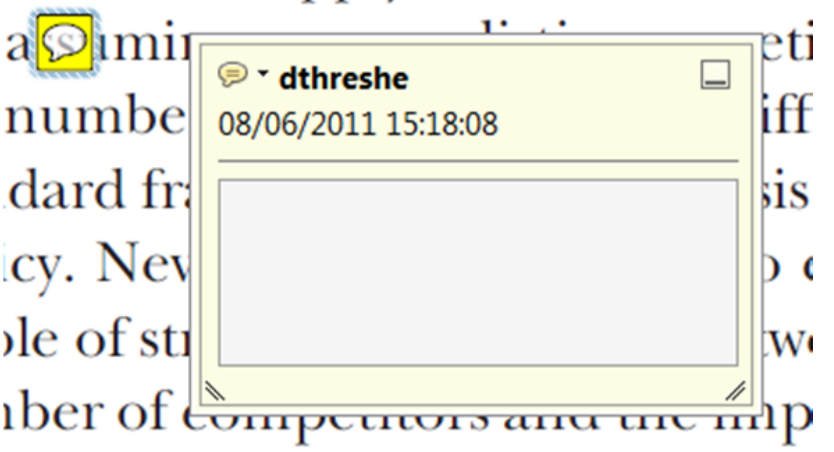

is that the structure of the secto. 
5. Attach File Tool - for inserting large amounts of text or replacement figures.

Inserts an icon linking to the attached file in the appropriate pace in the text.

How to use it

- Click on the Attach File icon in the Annotations section.

- Click on the proof to where you'd like the attached file to be linked.

- Select the file to be attached from your computer or network.

- Select the colour and type of icon that will appear in the proof. Click OK.

E N D

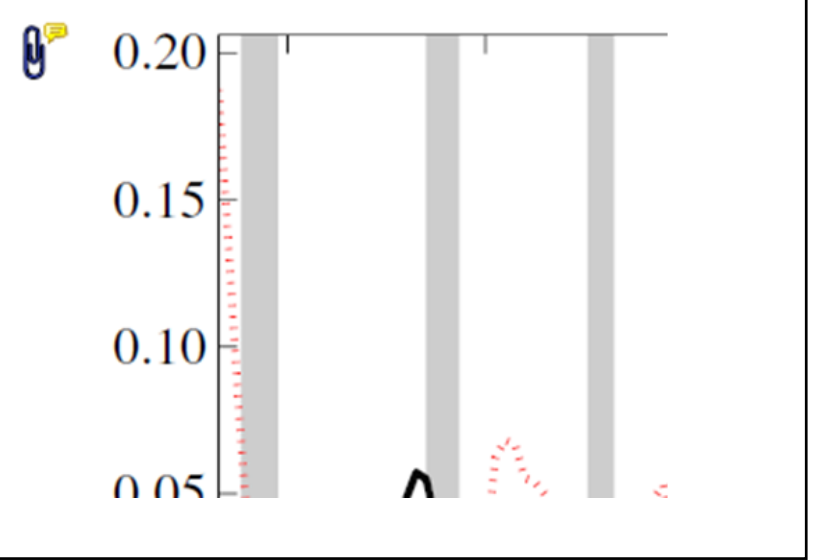

6. Add stamp Tool - for approving a proof if no corrections are required.

- Inserts a selected stamp onto an appropriate place in the proof.

\section{How to use it}

- Click on the Add stamp icon in the Annotations section.

- $\quad$ Select the stamp you want to use. (The Approved stamp is usually available directly in the menu that appears).

- Click on the proof where you'd like the stamp to appear. (Where a proof is to be approved as it is, this would normally be on the first page).

or the business cycie, starting with the on perfect competition, constant ret

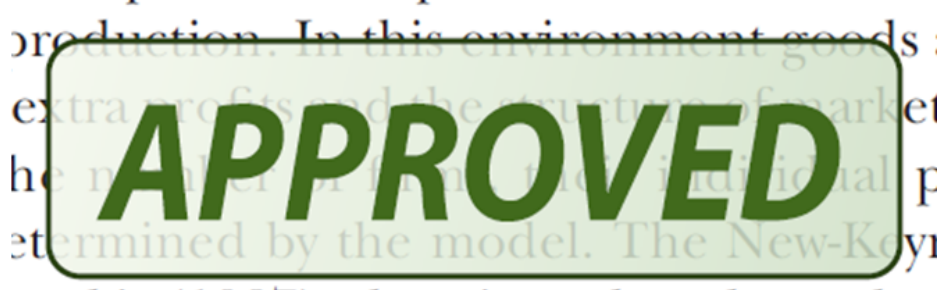
otaki (1987), has introduced produc general equilibrium models with nomin:

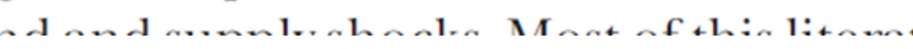

- Drawing Markups

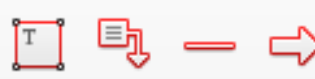

$0 \bigcirc \sqrt{6} \otimes$

\section{How to use it}

- Click on one of the shapes in the Drawing Markups section.

- Click on the proof at the relevant point and draw the selected shape with the cursor.

- To add a comment to the drawn shape, move the cursor over the shape until an arrowhead appears.

- Double click on the shape and type any text in the red box that appears.
7. Drawing Markups Tools - for drawing shapes, lines and freeform annotations on proofs and commenting on these marks.

Allows shapes, lines and freeform annotations to be drawn on proofs and for comment to be made on these marks.

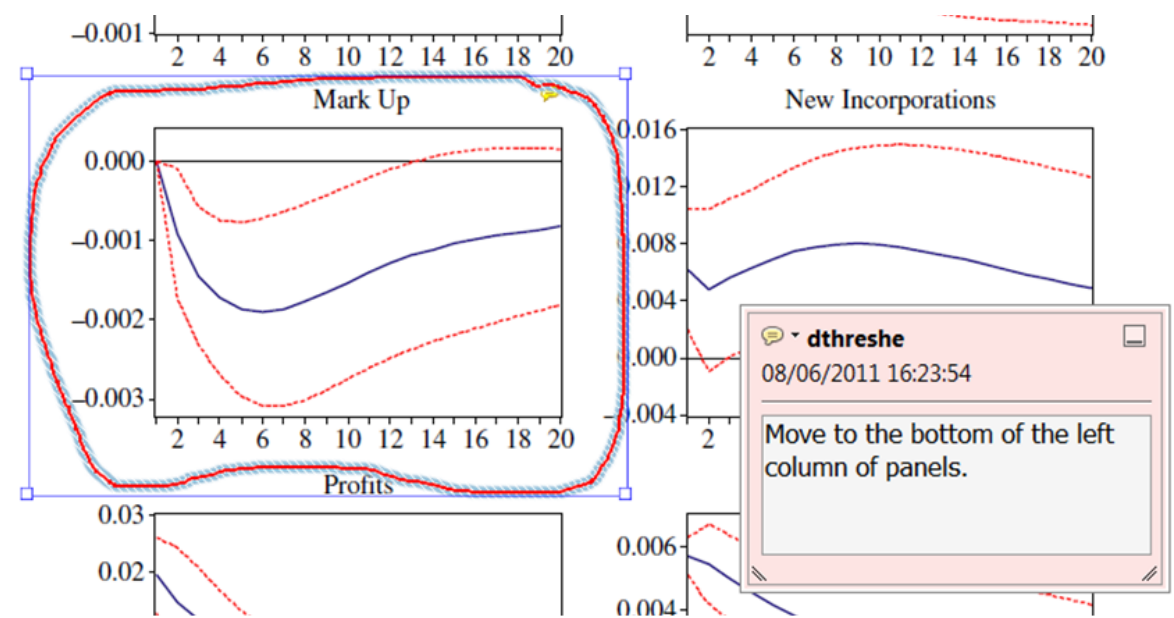

For further information on how to annotate proofs, click on the Help menu to reveal a list of further options:

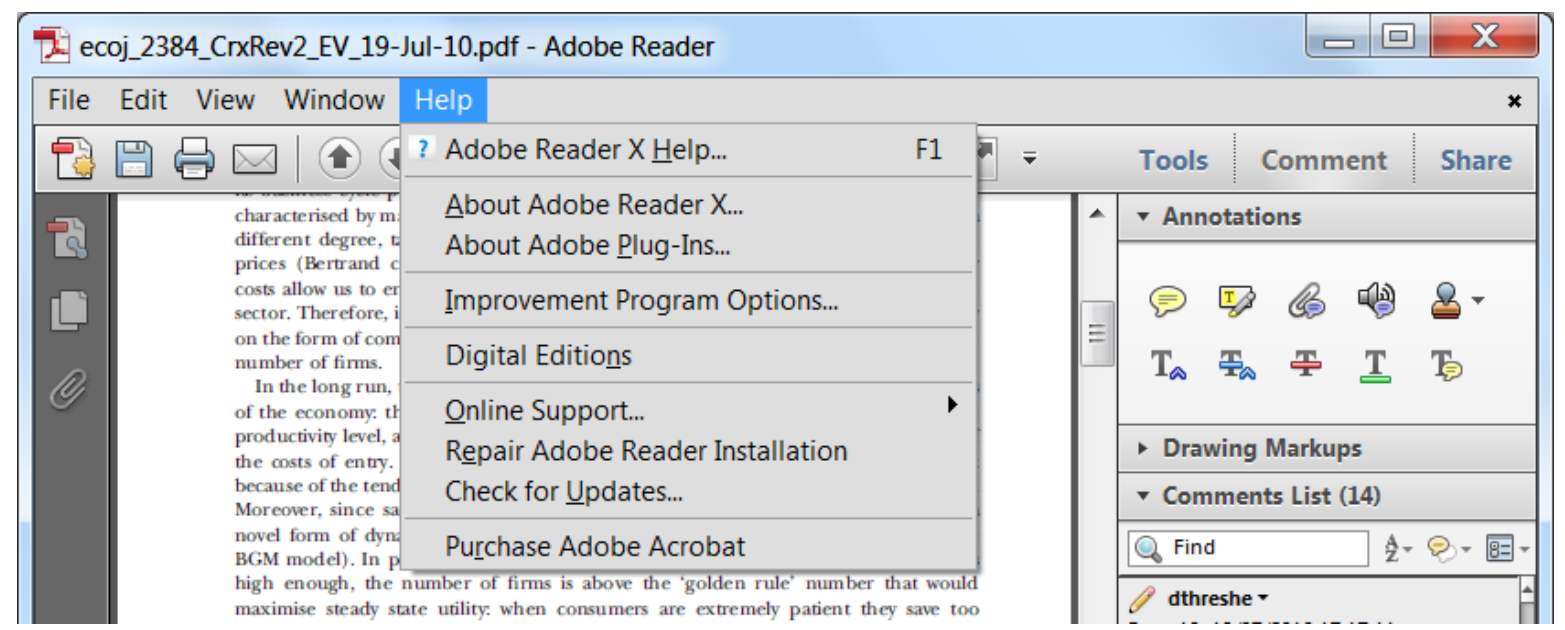

